\title{
Implantes de panturrilha: complicações, prevenção e tratamento
}

\section{Calf implants: complications, prevent and treatment}

\author{
Augusto César de Aguiar \\ TEIXEIRA $^{1}$ \\ Carla Colado Dib ${ }^{2}$
}

Trabalho realizado no Hospital Geral Andaraí, Rio de Janeiro, RJ, Brasil.

Artigo submetido pelo SGP (Sistema de Gestão de Publicações) da RBCP.

Artigo recebido: $12 / 5 / 2010$ Artigo aceito: 25/8/2010

\begin{abstract}
RESUMO
A inclusão de implantes de panturrilha para correção de atrofias e distrofias de membros inferiores vem sendo cada vez mais realizada. Nosso objetivo é avaliar, prevenir e tratar as possíveis complicações deste procedimento. São 21 anos de acompanhamento, 142 casos e sete complicações, sendo seis tratadas cirurgicamente, com remissão do problema.
\end{abstract}

Descritores: Pernas/cirurgia. Próteses e implantes/efeitos adversos. Elastômeros de silicone.

\section{SUMMARY}

The inclusion of calf implants to correct the atrophy and dystrophy of the inferior limb has been more achieve. Our objective is evaluated, prevent and treat the possible complications of this procedure. There are 21 years of fellow, 142 cases and seven complications, six of this were treated surgically with problem resolution.

Descriptors: Leg/surgery. Prostheses and implants/adverse effects. Silicone elastomers.

\section{INTRODUÇÃO}

As atrofias e hipotrofias das panturrilhas vêm sendo melhoradas com o emprego de implantes de silicone gel desde 1979. A princípio os implantes foram empregados em pacientes com sequelas de poliomielite ou doenças neuromusculares ${ }^{1}$, mas a partir da década de 80 passaram a ser utilizados com sucesso na correção de panturrilhas hipotróficas de origem constitucional, caracterizando uma correção estritamente estética² .

O procedimento cirúrgico é simples, seguro e eficaz, entretanto, como qualquer outro, apresenta um pequeno percentual de complicações.

Este trabalho propõe analisar e compreender tais complicações para que possamos preveni-las e tratá-las.

\section{MÉTODO}

No período de junho de 1988 a junho de 2009, foram realizadas 142 inclusões de implantes de panturrilhas em pacientes com hipotrofia ou atrofia das mesmas. A idade variou de 25 a 55 anos (média de 36 anos), sendo 128 $(90,1 \%)$ do sexo feminino e $14(0,9 \%)$ do sexo masculino. Dentre esses pacientes, um apresentou sintomas de compressão, dois, hematomas, dois, ruptura da prótese, uma, herniação, e uma, hipertrofia de cicatriz, totalizando sete $(4,9 \%)$ complicações.

Todos os pacientes foram tratados cirurgicamente, com exceção da cicatriz hipertrófica, que foi submetida a infiltração de corticoide local, com resultado satisfatório.

1. Membro Titular da Sociedade Brasileira de Cirurgia Plástica (SBCP); Cirurgião plástico do Hospital Geral Andaraí, Rio de Janeiro, RJ, Brasil.

2. Membro Especialista da SBCP; Cirurgião plástico do Hospital Geral Andaraí, Rio de Janeiro, RJ, Brasil. 
Os dois casos de hematomas foram tratados com drenagem dos mesmos, e recolocação imediata das próteses. A hérnia muscular foi tratada com retirada do implante, herniorrafia através de outra incisão e recolocação imediata do implante. Nos dois pacientes que apresentaram ruptura do implante, com mais de 10 anos de cirurgia, estes foram retirados, sendo um pela região poplítea (Figura 1) e outro por uma incisão prolongada verticalmente na panturrilha, devido à dificuldade de retirada do implante (Figura 2), sem inclusão de implante por preferência dos pacientes (Figura 3). No caso de compressão (possível síndrome compartimental), os implantes foram retirados imediatamente pela incisão poplítea (Figura 4). Neste caso, tinham sido colocados dois implantes em cada panturrilha, um medial e outro lateral.

\section{RESULTADOS}

Dentre os sete pacientes que apresentaram complicações, seis foram submetidos a um novo procedimento, e todos obtiveram remissão dos sintomas. O paciente com síndrome compressiva e os pacientes com ruptura da prótese não quiseram se submeter a nova inclusão de implante. Os outros três pacientes que concordaram com novo implante de prótese apresentaram resultados satisfatórios e retorno do contorno da panturrilha.

\section{DISCUSSÃO}

Um dos princípios médicos diz que podemos realizar qualquer procedimento se pudermos prevenir ou estivermos aptos a reconhecer e tratar as complicações.

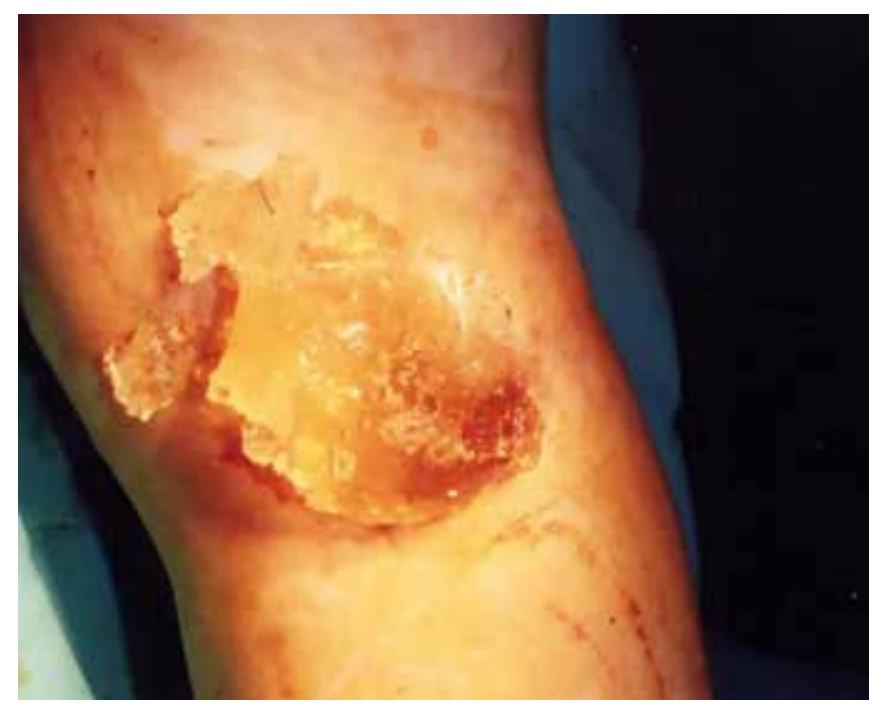

Figura 1 - Rotura da prótese.
As complicações podem ser prevenidas se observados alguns cuidados: realizar anamnese bem detalhada; evitar tornozelos finos; conhecer a técnica cirúrgica e o plano exato de inclusão da prótese; avaliar a necessidade do uso do expansor; quando necessário colocar dois implantes em cada perna, fazê-lo em lojas diferentes e com seis meses de intervalo entre um implante e outro.

As complicações podem ser imediatas, como hematomas e síndrome compartimental, ou tardias, como ruptura da prótese e herniação fascio-muscular ${ }^{1}$ (Figura 5).

Os hematomas são facilmente diagnosticados no pósoperatório imediato, o paciente refere dor local, apresenta edema crescente e saída de sangue pela incisão cirúrgica (Figura 6). Seu tratamento é retirar a prótese, drenar o hematoma e recolocar a prótese de imediato.

Síndrome compartimental é a mais delicada e temida das complicações ${ }^{3}$. Medicamentos para reduzir a capilaridade e o edema associado à fasciotomia lateral e medial é o tratamento ideal se realizados nas primeiras 12 horas de evolução $0^{4-6}$. Dor, paralisia, paresia ou hiperestesia cutânea, e ausência de pulso são os sintomas clássicos ${ }^{3}$, sendo a medida da pressão intracompartimental necessária apenas em pacientes em coma ${ }^{7}$. A retirada da prótese também pode solucionar o problema.

É importante o diagnóstico diferencial com distrofia simpático-reflexa ou síndrome da dor complexa regional $(\mathrm{SDCR})^{8}$, que é caracterizada por dor intensa, edema e calor, e, se não tratada, evolui para distrofia e atrofia. $\mathrm{O}$ tratamento

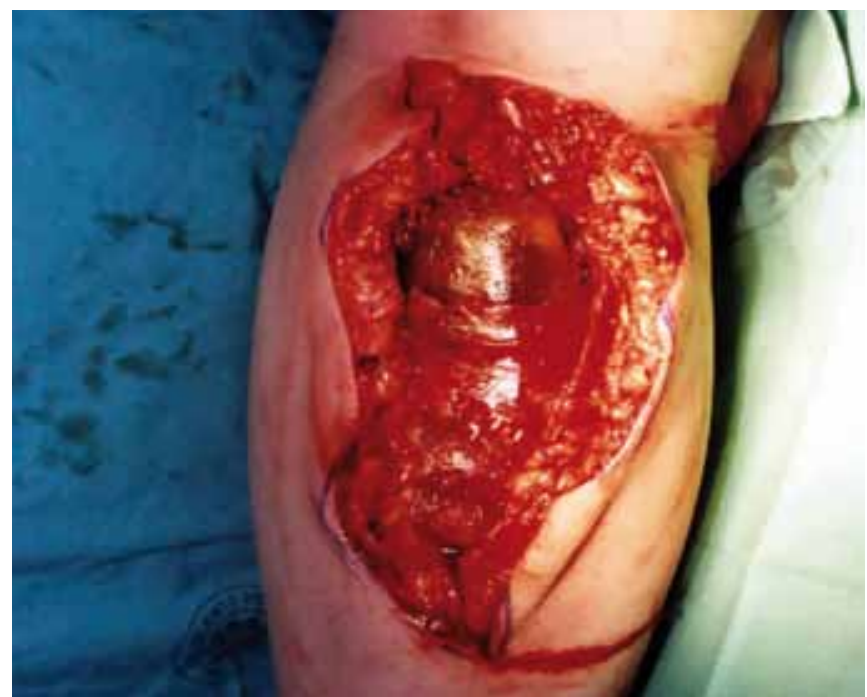

Figura 2 - Rotura da prótese, sendo necessária a abertura vertical. 


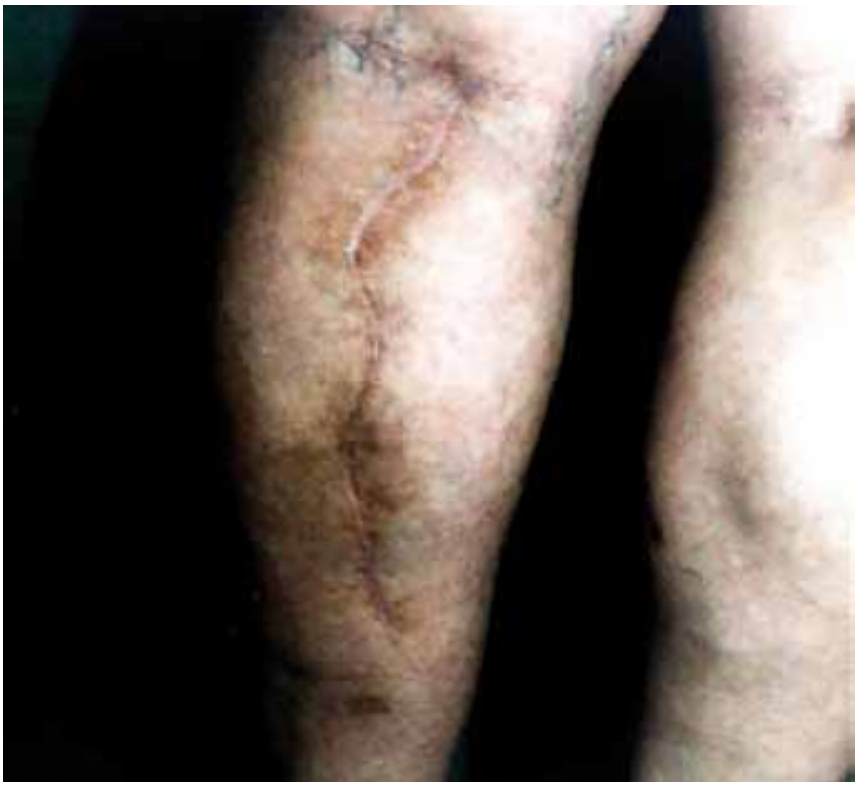

Figura 3 - Pós-operatório da cicatriz vertical.

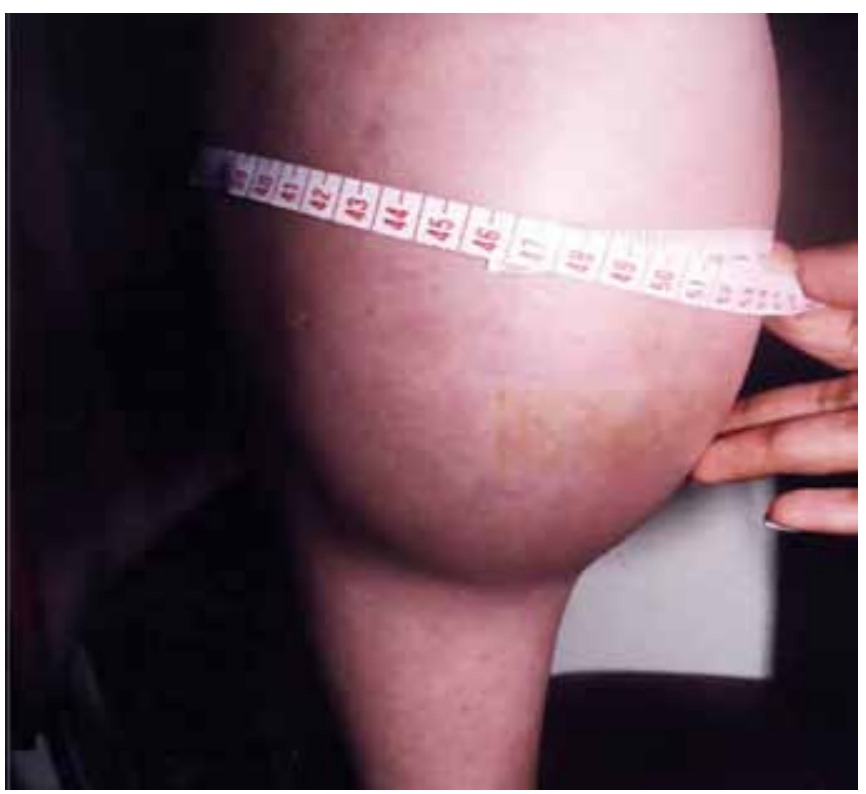

Figura 4-Grande edema levando a síndrome compartimental.

da SDCR é multidisciplinar, e se tratado imediatamente com corticoterapia o quadro não evolui ${ }^{8}$.

Nos casos de ruptura da prótese, que geralmente ocorre anos após a inclusão da mesma, esta deve ser retirada e lavada a loja. Colocar ou não um novo implante fica a critério do paciente e do cirurgião.

As herniações musculares devem ser tratadas com sutura da fáscia através de outra incisão próxima à hérnia e reposicionamento do implante.

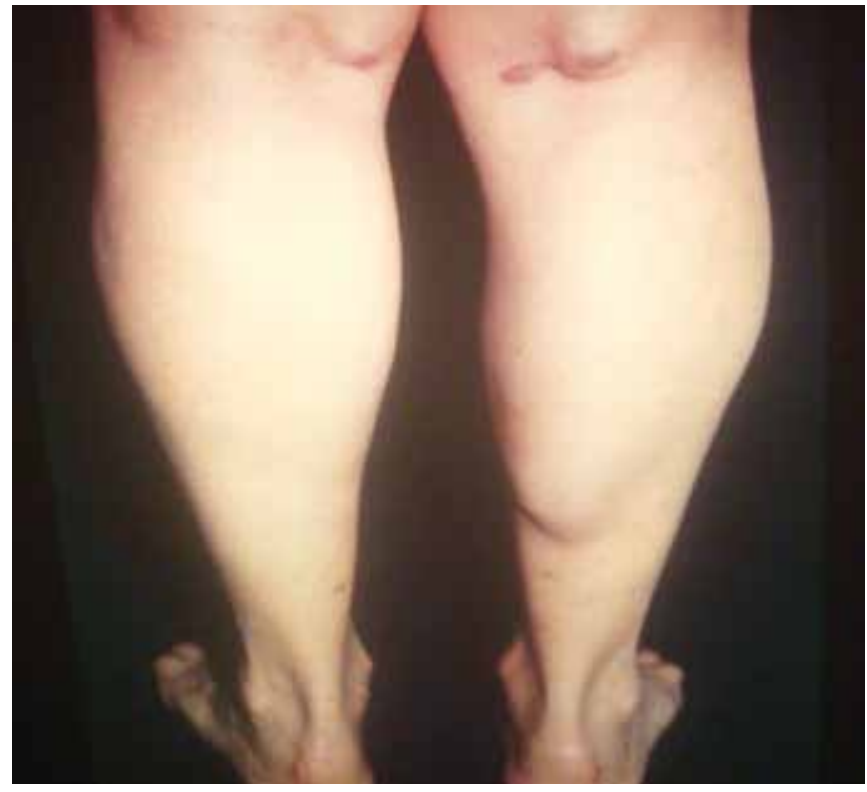

Figura 5 - Herniação das próteses de panturrilha e coxa.

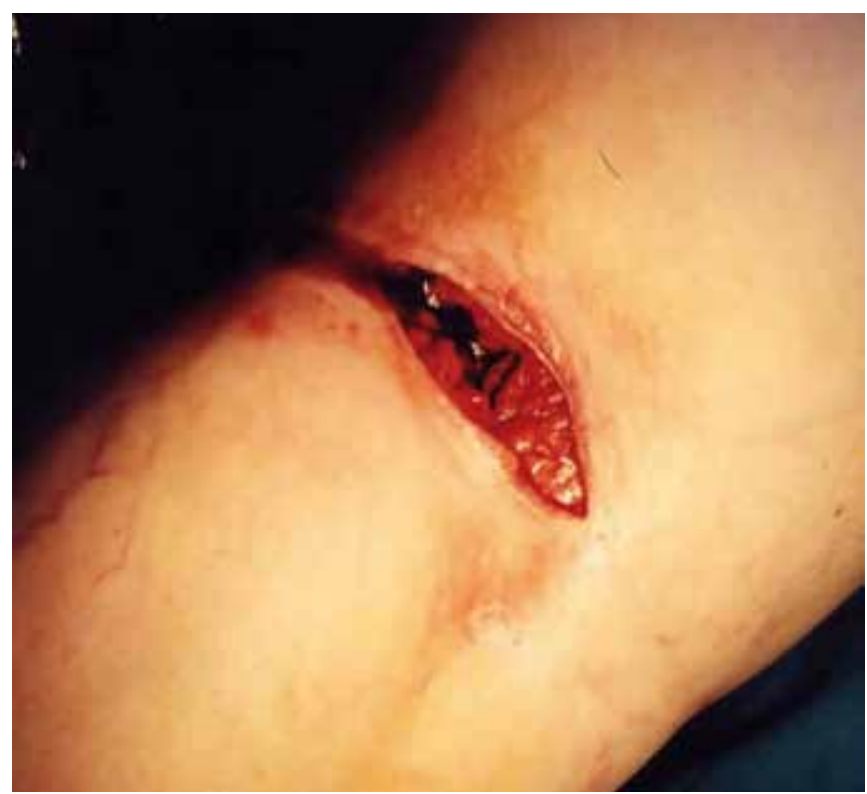

Figura 6 - Hematoma, com saida de sangue pela incisão cirúrgica.

\section{CONCLUSÃO}

A maioria dos implantes de panturrilhas preenche os requisitos necessários para correção das deformidades atróficas dos membros inferiores.

Trata-se de uma cirurgia segura e de fácil execução, entretanto, o conhecimento das doenças inerentes ao procedimento é imprescindível para prevenção, diagnóstico e tratamento das complicações. 


\section{REFERÊNCIAS}

1. Glicenstein J. Corrección de las amiotrofias de los miembros por inclusión de prótesis de silicona. Rev Bras Cir. 1979;69(3/4):117-22.

2. Montellano L. Plástica de panturrilha. Anais do XXI Congresso Brasileiro de Cirurgia Plástica;1984.

3. Mubarak SJ, Hargens AR. Síndromes compartimentais agudas. Surg Clin North Am. 1983;63(3):539-65.

4. Matsen FA $3^{\text {rd }}$, Winquist RA, Krugmire RB Jr. Diagnosis and management of compartmental syndromes. J Bone Joint Surg Am. 1980;62(2):286-91.
5. Mubarak SJ, Owen CA. Double-incision fasciotomy of the leg for decompression in compartment syndromes. J Bone Joint Surg Am. 1977;59(2):184-7.

6. Ernist C, Stanley J. Current therapy in vascular surgery. $3^{\mathrm{a}}$ ed. Missouri: Mosby;1995. p.644-50.

7. Whitesides TE, Haney TC, Morimoto K, Harada H. Tissue pressure measurements as a determinant for the need of fasciotomy. Clin Orthop Relat Res.1975;(113):43-51.

8. Sakata R. Síndrome complexa de dor regional. Dor Artmed. 2009;57:701-10.

\section{Correspondência para:}

Augusto César de Aguiar Teixeira

Avenida Nossa Senhora de Copacabana, 1183 - sala 302 - Copacabana - Rio de Janeiro, RJ, Brasil CEP: 22070-011

E-mail: augustocteixeira@hotmail.com 